\title{
İntravezikal BCG immunoterapisini takiben gelişen Reiter sendromu: Olgu sunumu
}

\author{
Reiter's syndrome occurred following intravesical BCG immunotherapy: Case presentation
}

\author{
Fatih Elbir ${ }^{1}$, Ramazan Topaktaş², İsmail Başıüyükk ${ }^{1}$, Abdullah Armağan ${ }^{1}$
}

\section{ÖZET}

Intravezikal Bacillus Calmette Guerin (BCG), yüzeyel mesane karsinomlarının tedavisinde etkin ve güvenilir bir yöntemdir. Klinik olarak çok etkili olan bu tedavi yöntemi birçok yan etkiye sahiptir. Reiter Sendromu ise bu yan etkiler arasında en nadir görülenidir. Bu yazıda BCG instilasyonu sonrası gelişen ve değişik bir klinik görünüm içeren Reiter Sendromu vakasını sunuyoruz

Anahtar kelimeler: İnvaziv olmayan mesane tümörü, intravezikal Bacillus Calmette Guerin (BCG), Reiter sendromu

\section{GíRiş}

İntravezikal Basillus Calmette-Guerin (BCG), orta ve yüksek derece yüzeysel mesane kanserinde ve karsinoma in situda 1976'dan bu yana kullanilan progresyon ve nüks riskinini azalttığı kanıtlanmış bir tedavidir. $\mathrm{Bu}$ tedavinin en s1k görülen yan etkisi sistittir (\% 90) [1]. Artralji ve reaktif artrit ise nadir görülen yan etkilerinden biridir $(\% 0,5)$ [1]. Artrit, gonokoksik olmayan üretrit ve konjonktivit semptomları ile karakterize olan Reiter Sendromu (reaktif artrit), ilk defa 1916 yılında Reiter tarafindan tanımlanmıştır [2]. Deri, mukoz membranlar, gastrointestinal traktus, kardiyovasküler sistem tutulumu görülebilir [2,3]. Enterik ve ürojenik enfeksiyonlar olayı tetikler. Eklem bulguları asimetrik artit şeklindedir ve en çok ağırlık taşıyan eklemler ve sakroiliak eklem tutulumu olur [2-4]. Bu yazıda, yüzeyel mesane tümörlü hastaya uygulanan intravezikal BCG immunoterapisi sonrası ender görülen

\begin{abstract}
Intravesical instillation of Bacillus Calmette Guerin (BCG) is used in the treatment of patients with superficial bladder carcinoma with efficacy and safety. Although clinically very effective this method is associated with a variety of side effects. In these side effects, Reiter's Syndrome is occurred most rare. We report here the case of Reiter's Syndrome following BCG instillation with a different clinical manifestation.
\end{abstract}

Key words: Non-invasive bladder carcinoma, intravesical instillation of Bacillus Calmette Guerin (BCG), Reiter's syndrome

bir komplikasyon olan Reiter sendromlu hastamızı sunmayı amaçladık.

\section{OLGU}

Yetmiş bir yaşında erkek hasta acil servise yüksek ateş, her iki gözde kızarıklık, ağrı ve sulanma, dizlerde ağnı ve hareket kısıtlılığı şikâyetleriyle başvurmuş. Hastanın bilinen mesane tümörü öyküsü mevcut. On sekiz ay önce yapılan transüretral mesane tümörü rezeksiyonu (tur-m), G1pTa ve CIS (karsinoma insitu) olarak rapor edilmiş. Daha sonra SWOG (Southwest Oncology Group) protokolüne uygun olarak operasyon sonrası ikinci haftada 6 haftalık BCG tedavisi başlanmış. Üçüncü ay sistoskopi kontrolünde herhangi bir patolojiye rastlanılmamış ve sonrasında 3 haftalık BCG tedavisi almış. BCG tedavisi sonrası on altıncı günde hastada iki taraflı diz ağrıları, hareket kısıtlı1ı̆̆ı, gözlerde kızarıklık, sulanma ve ağr1 meydana geldi. Tıbbi öyküsünde bilinen romatolojik ve göz hastalığı bulunmayan

\footnotetext{
${ }^{1}$ Bezmialem Vakıf Üniversitesi, Tip Fakültesi Üroloji AD, İstanbul, Türkiye

${ }^{2}$ Diyarbakır Gazi Yaşargil Eğitim ve Araştırma Hastanesi, Üroloji Kliniği Diyarbakır, Türkiye
}

Yazışma Adresi /Correspondence: Fatih Elbir,

Bezmialem Vakif Üniversitesi, Tıp Fakültesi Üroloji ABD, İstanbul, Türkiye Email: drfatihelbir@gmail.com

Geliş Tarihi / Received: 21.11.2014, Kabul Tarihi / Accepted: 09.03.2015

Copyright @ Dicle Tıp Dergisi 2015, Her hakkı saklıdır / All rights reserved 
hastanın, geçirilmiş apendektomi dışında başka cerrahi öyküsü olmadığı saptandı. Hipertansiyon nedeniyle anjiotensin reseptör inhibitörü dışında başka ilaç kullanmadığı görüldü.

Laboratuvar incelemelerinde WBC:19.400/ $\mathrm{mm}^{3}, \quad \mathrm{Hb}: 13,5 \mathrm{~g} / \mathrm{dl}, \quad \mathrm{Plt}: 175.000 / \mathrm{mm}^{3}$, ESR:73 mm/h, CRP:19,8 mg/dl, RF:5,9 IU/ML, HLA-B27 (-) olarak tespit edildi. İdrar ve kan kültürlerinde üreme saptanmadı, septik artrit ön tanısı için yapılan eklem sıvı ponksiyon kültürü de negatif olarak sonuçlandı. İki yönlü akciğer grafisinde de herhangi bir patolojiye rastlanmadi.

Reiter Sendromu tan1s1, enfeksiyon ön tan1s1 dişlandıktan ve hastada sebat eden konjuktivit, bilateral diz eklem artriti, yüksek ateş sebebiyle konuldu. Hastaya ilk 3 gün profilaktik 1 gr Seftriakson (intravenöz) ve non-steroid antiinflamatuar ilaç (NSAİ) tedavisi başlanılmasına rağmen semptomlar gerilemeyince antibiyoterapi sonlandırıldı ve günlük Prednizolon $25 \mathrm{mg}$ intramuskuler olarak uyguland1. Semptomlar bu tedavinin ikinci gününde gerilemeye başladı ve bir hafta sonra steroid tedavisi sonlandırıldı. Birinci ay sonunda şikayetlerinin tamamen kaybolması üzerine NSAİ tedavisi de kesildi. 7 aylık takibinde şikayetlerinin tekrarlamadığ 1 görüldü.

\section{TARTIŞMA}

Intravezikal Basillus Calmette-Guerin (BCG) tedavisi uzun yıllar, orta ve yüksek derece yüzeysel mesane tümörleri ve CIS'da progresyon ve nüksü engellediği kanıtlanan bir tedavi modalitesidir. \%95 hastada herhangi bir komplikasyon görülmezken geri kalan \%5'lik hasta diliminde yüksek olmayan ateş, döküntü, hematüri, sistit gibi iyi bilinen komplikasyonlar görülebilmektedir [5]. BCG instilasyonunun romatizmal yan etkileri nadir görülürken spesifik olarak aseptik poliartrit gibi yan etkisinin görülmesi çok daha nadir görülür [6]. Lamm ve arkadaşlarının [5] yayınladığ 2602 hastayı içeren seride BCG tedavisi sonrası artrit görülme sıklı̆̆ $\% 0,5$ olarak saptanmıştır. Artritin özelliği, genellikle tek taraflı ve özellikle diz gibi ağırlık taşıyan eklemlerde olmakla birlikte NSAİ tedaviye erken cevap veriyor olmasıdır. Reiter sendromu asimetrik artrit, üretrit, konjuktivit ve genellikle HLA-B27 varlığg ile karakterizedir [7,8]. Vakamızda HLA-B27 negatif olmasına rağmen bu durum Reiter tanısını dişlamamaktadır. Tedavide, sadece NSAİ kullanımı veya NSAİ ile prednizolon ya da izoniazid kullanımı önerilmektedir. Eğer NSAİ tedaviye yanıt az veya yok, ya da hastada ciddi semptomlar içeren sistemik bir enfeksiyon mevcutsa tedaviye izoniazid ve rifampisin eklenmelidir [1,9]. Tedavi seçimi hastanın klinik durumu ve gidişatına göre klinisyenin kararına bağlıdır. Bizim vakamızda sadece NSAİ tedaviye cevap alınamadığ 1 için Prednizolon ile NSAI'’ın beraber kullanımı tercih edildi nitekim ikinci günde semptomlar geriledi.

Sonuç olarak, mesane tümörü varlığı ve buna bağlı kullanılan intravezikal BCG tedavisi sonrasinda, oligo-poliartrit, konjuktivit ve sistiti gelişen hastalarda, ayırıcı tanıda Reiter sendromunu da düşünüp, olası komplikasyonlar gelişmeden uygun tedavinin erken dönemde planlanması gerekmektedir.

\section{KAYNAKLAR}

1. Lamm DL, Stogdill VD, Stogdil BJ, Crispen RG. Complications of Bacillus Calmette-Guerin immunotherapy in 1278 patients with bladder cancer. J Urol 1986;135:272-274.

2. Odom RB, Jome WD, Berger TG. Andrews' diseases of the skin. $9^{\text {th }}$ ed. United States of America: WB Saunders Company; 2000.

3. Parker CT, Thomas D. Reiter's syndrome and reactive arthritis. J Am Osteopath Assoc 2000;100:101-104.

4. Graham RB, Champion RH, Burton JL. Reiter's disease, Ebling FJG Textbook of Dermatology. $5^{\text {th }}$ ed. Turin: Blackwell scientific publications; 1992.

5. Lamm DL, Van Der Mejden ADPM, Morales A, et al. Incidence and treatment of Bacillus Calmette-Guerin intravesical therapy in superficial bladder cancer. J Urol 1992; 147:596-600.

6. Kodali VR, Clauge RB. Arthritis after BCG vaccine in a healthy woman. J Intern Med 1998; 244:183-184.

7. Pancaldi P, Van Linthoudt D, Alborino D, et al. Reiter's Syndrome after intravesical Bacillus Calmette-Guerin treatment for superficial bladder carcinoma. Br J Rheumatol 1993;32:1096-1098.

8. Wu IB, Schwartz RA. Reiter's syndrome: the classic triad and more. J Am Acad Dermatol 2008;59:113-121.

9. Ng KL, Chua CB. Reiter's syndrome post intravesical Bacillus Calmette-Guerin instillations. Asian J Surg 2014, http:// dx.doi.org/10.1016/j.asjsur.2014.01.016 